Perspective

\section{Glucagon-like Receptor 1 Agonists in the Treatment of Type 2 Diabetes}

\author{
Theano Penlioglou, Nikolaos Papanas* \\ Diabetes Centre, Second Department of Internal Medicine, Democritus \\ University of Thrace, University Hospital of Alexandroupolis, Dragana, \\ Alexandroupolis 68100, Greece.
}

Corresponding Author: Nikolaos Papanas. Email: papanasnikos@yahoo.gr.

During the last decades, there has been a huge increase in the prevalence of type 2 diabetes mellitus (T2DM), mostly due to the Western lifestyle ${ }^{[1,2]}$. T2DM and its vascular complications increase patient morbidity, hospitalisations and healthcare costs ${ }^{[3,4]}$. Thus, it is beyond doubt that we need medication which can confer some improvement in the underlying pathophysiological factors leading to T2DM and its complications.

Glucagon-like peptide 1 receptor agonists (GLP-1RAs) are a class of antidiabetic agents, which was introduced in the 21st century. They successfully target not only blood glucose control but also obesity in patients with T2DM ${ }^{[5,6]}$. Currently, exenatide, liraglutide, lixisenatide, albiglutide and dulaglutide are already on the market ${ }^{[5,7]}$. The newest agent is semaglutide ${ }^{[5-7]}$.

All GLP-1RAs are used subcutaneously. Albiglutide, dulaglutide and semaglutide show a long action and are administered once weekly ${ }^{[6,8-11]}$. Liraglutide is used once daily. Exenatide exists in two preparations: a quick acting used twice per day, and a long-acting used once per week ${ }^{[6,8-11]}$. An oral form of semaglutide is currently under development ${ }^{[6,8-11]}$.

GLP-1 RAs mainly act by activating the GLP-1 receptors in pancreatic beta cells to stimulate glucose-dependent insulin secretion. Additionally, they reduce appetite and delay gastric emptying, eventually leading to reduced food intake ${ }^{[6,8-10]}$. They can be used either as monotherapy or an add-on therapy to other antidiabetic agents, including insulin, in T2DM $^{[11-13]}$. GLP-1RAs have very recently been recommended as the second antidiabetic agent after metformin in patients with established atherosclerotic cardiovascular disease and chronic kidney disease ${ }^{[14]}$. However, they should not be used together with dipeptidyl peptidase-4 inhibitors ${ }^{[10-13]}$. As regards type 1 diabetes mellitus, they have been studied but they are not currently approved ${ }^{[9,11,13]}$.

The advantages of GLP-1RAs include: (a) efficacy (reduction of glycated haemoglobin $0.6-1.9 \%$ in a period of $24-30$ weeks); (b) absence of hypoglycaemias; (c) weight reduction; (d) reduction of appetite; (e) reduction of fatty liver infiltration. These actions are significant and clinically meaningful (see Table 1$)^{[5,10,11-13,15,16]}$. 
Table 1. Major efficacy results of trials with GLP-1RAs.

\begin{tabular}{lllll}
\hline GLP-1RAs & Dose & Trial & HbA1c reduction & Weight loss \\
\hline Liraglutide & $0.6-1.8 \mathrm{mg} /$ once daily & LEAD-6 & $1.48 \%$ in 26 weeks & $0.2-2.8 \mathrm{~kg}$ \\
Exanatide & $5-10 \mu \mathrm{g} /$ twice daily & DURATION-5 & $1.5 \%$ in 30 weeks & $1.1-2.9 \mathrm{~kg}$ \\
& $2 \mathrm{mg} / \mathrm{once}$ weekly & DURATION-5 & $1.9 \%$ in 30 weeks & $1.3-2.3 \mathrm{~kg}$ \\
Albiglutide & $30-50 \mathrm{mg} /$ once weekly & HARMONY-7 & $0.78 \%$ in 32 weeks & $0.4-1.1 \mathrm{~kg}$ \\
Dulaglutide & $1.5 \mathrm{mg} /$ once weekly & AWARD-6 & $1.42 \%$ in 26 weeks & $0.9-3.4 \mathrm{~kg}$ \\
Lixisenatide & $10-20 \mu \mathrm{g} /$ once daily & GetGoal-X & $0.79 \%$ in 24 weeks & $0.3-2.8 \mathrm{~kg}$ \\
\hline
\end{tabular}

Regarding their combination with other antidiabetic agents, there are interesting results from some trials. In a study including patients treated with a GLP-1RA together with a sodium glucose transporter 2 inhibitor (SGLT2), the mean reduction of glucose was $2.2 \mathrm{mmol} / \mathrm{L}(39.6 \mathrm{mg} / \mathrm{dL})(p<0.0004)$ after 6 months ${ }^{[17]}$. This therapeutic combination achieved not only adequate glycaemic control, but also weight loss $(2.1 \mathrm{~kg} ; p<0.00003)$ and decrease of blood pressure ${ }^{[17]}$. In addition, $34.3 \%$ of patients achieved $\mathrm{Hb} 1 \mathrm{Ac}$ levels $<7 \%$ and weight loss $>5 \%$, without hypoglycaemias ${ }^{[17]}$. These results are also supported by another real-world observational study in with patients receiving a GLP-1RA in combination with metformin and a SGLT-2 inhibitor ${ }^{[18]}$.

The main adverse effects of GLP-1RAs are gastrointestinal: nausea, vomiting, diarrhoea and abdominal complaints (see Table 2) ${ }^{[19]}$. However, these are mostly self-limited over time ${ }^{[19]}$. Another adverse effect is injection-site reactions ${ }^{[19]}$. Moreover, there are indications that incretin-based therapies may cause pancreatic diseases. Nevertheless, according to real-world evidence, the risk of pancreatic disease associated with add-on GLP-1RAs to metformin therapy appears to be no higher than that associated with other antidiabetic agents ${ }^{[20]}$.

Table 2. Safety and tolerability of GLP-1RAs.

\begin{tabular}{|c|c|c|c|c|c|c|}
\hline GLP-1RAs & Dose & Trial & $\begin{array}{c}\text { Major } \\
\text { hypoglycemia }\end{array}$ & $\begin{array}{c}\text { Minor } \\
\text { hypoglycemia }\end{array}$ & $\begin{array}{c}\text { Gastrointestinal } \\
\text { adverse effects } \\
\text { (nausea/vomiting/ } \\
\text { diarrhoea) }\end{array}$ & $\begin{array}{l}\text { Withdrawal } \\
\text { due to } \\
\text { adverse } \\
\text { effects }\end{array}$ \\
\hline Liraglutide & $0.6-1.8 \mathrm{mg} / \mathrm{once}$ daily & LEAD-6 & $0 \%$ & $2 \%$ & $25 \%$ (Nausea) & $6 \%$ \\
\hline \multirow[t]{2}{*}{ Exanatide } & $5-10 \mu \mathrm{g} / \mathrm{twice}$ daily & DURATION-5 & $0 \%$ & $0 \%$ & $35 \% / 9 \% / 4 \%$ & $5 \%$ \\
\hline & 2 mg/once weekly & DURATION-5 & $0 \%$ & $0 \%$ & $14 \% / 5 \% / 9 \%$ & $5 \%$ \\
\hline Albiglutide & 50 mg/once weekly & HARMONY-2 & $0 \%$ & $0 \%$ & $9 \% / 3 \% / 13 \%$ & $13 \%$ \\
\hline Dulaglutide & 1.5 mg/once weekly & AWARD-6 & $0 \%$ & $9 \%$ & $20 \% / 7 \% / 12 \%$ & $6 \%$ \\
\hline Lixisenatide & 10-20 $\mu \mathrm{g} /$ once daily & GetGoal-M & $0 \%$ & $2 \%$ & $22 \% / 9 \% / 10 \%$ & $7 \%$ \\
\hline
\end{tabular}

Obviously, the need for injection may discourage some patients, but this can easily be overcome with patient education ${ }^{[16,19]}$. Moreover, the new pens and (especially) the once-weekly injection of some compounds render them more user friendly ${ }^{[11,16,19]}$. Another consideration is administration and ease of use. For example, albiglutide needs reconstruction before injection, making its use difficult for some patients, including those with visual or dexterity issues ${ }^{[11,16,19]}$.
The most important challenge for GLP-1RAs is, as indeed for all antidiabetic agents, the potential cardioprotective actions ${ }^{[21,22]}$. In this context, GLP-1RAs have demonstrated: (a) slight improvements in arterial pressure, lipid parameters and inflammation in humans; (b) improvements in heart failure and myocardial infarction in the experimental setting ${ }^{[21-24]}$.

Of particular relevance, GLP-1RAs exhibit important differences in their cardiovascular effects in 
large clinical trials. Indeed, liraglutide and semaglutide significantly reduce the risk of major adverse cardiac events ${ }^{[25,26]}$. By contrast, once-weekly exenatide and lixisenatide have shown a neutral cardiovascular effect: safety but no benefit ${ }^{[27,28]}$. These differences need to be appreciated in clinical practice, especially when prescribing antidiabetic treatment to patients with known cardiovascular morbidity ${ }^{[29,30]}$.

Importantly, in the most recent cardiovascular outcomes trial $^{[31]}$, once-weekly albiglutide reduced the primary cardiovascular endpoint by $22 \%$, exhibiting superiority compared with placebo $(p=0.0006)$. This trial further enhances the importance of GLP1RAs, especially in patients with established cardiovascular disease ${ }^{[31,32]}$.

Furthermore, there is recent evidence that that GLP-1RAs may improve the natural history of diabetic complications. A pharmacovigilance meta-analysis has demonstrated that reduced incidence of retinopathy with GLP-1RAs, as compared to other antidiabetic agents ${ }^{[33]}$. Importantly, GLP-1RAs appear to exert an additional protective role in the kidneys. According to real-world evidence, their use in patients with low estimated glomerular filtration rate (eGFR) was related to less pronounced reduction in eGFR ( -0.80 vs. $\left.-1.03 \mathrm{~mL} / \mathrm{min} / 1.73 \mathrm{~m}^{2}, p=0.0005\right)$, as compared with other therapies, while $\mathrm{HbA} 1 \mathrm{c}$ was significantly reduced as well ${ }^{[34]}$.

Finally, it is now being increasingly appreciated that GLP-1RAs can be excellently be combined with basal insulin ${ }^{[32]}$. In this more modern combination, GLP-1RAs target post-prandial hyperglycaemia, while

\section{REFERENCES}

1. Cho NH, Shaw JE, Karuranga S, Huan g Y, da Rocha Fernandes JD, Ohlrogge AW, Malanda B. IDF Diabetes Atlas: Global estimates of diabetes prevalence for 2017 and projections for 2045. Diabetes Res Clin Pract. 2018; 138: 271-281.

2. Hu FB, Satija A, Manson JE. Curing the diabetes pandemic: the need for global policy solutions. JAMA. 2015; 313: 2319-2320.

3. Papatheodorou K, Banach M, Edmonds M, Papanas N, Papazoglou D. Complications of Diabetes. J Diabetes Res. 2015; 2015: 189525.

4. Seuring T, Archangelidi O, Suhrcke M. The economic costs of type 2 diabetes: a global systematic review. Pharmacoeconomics. 2015; 33: 811-831.

5. Prasad-Reddy L, Isaacs D. A clinical review of GLP-1 receptor agonists: efficacy and safety in diabetes and beyond. Drugs Context. 2015; 4: 212283. basal insulin targets fasting glucose. Nowadays, fixed GLP-1RAs+basal insulin combinations used as a single daily injection in the same pen are available to increase patient compliance ${ }^{[32]}$.

In conclusion, GLP-1RAs are antidiabetic agents with many advantages ${ }^{[5,8,14,35]}$. Their beneficial actions are increasingly being appreciated in the treatment of T2DM.

\section{CONFLICTS OF INTEREST}

This perspective was written independently. The authors did not receive financial or professional help with the preparation of the manuscript. N. Papanas has been an advisory board member of TrigoCare International, Abbott, AstraZeneca, Elpen, MSD, Novartis, Novo Nordisk, Sanofi-Aventis and Takeda; has participated in sponsored studies by Eli Lilly, MSD, Novo Nordisk, Novartis and Sanofi-Aventis; received honoraria as a speaker for AstraZeneca, Boehringer Ingelheim, Eli Lilly, Elpen, Galenica, MSD, Mylan, Novartis, Novo Nordisk, Pfizer, Sanofi-Aventis, Takeda and Vianex; and attended conferences sponsored by TrigoCare International, AstraZeneca, Boehringer Ingelheim, Eli Lilly, Novartis, Novo Nordisk, Pfizer and Sanofi-Aventis.

\section{AUTHORS' CONTRIBUTIONS}

N.P. conceived the perspective. T.P. wrote the first draft. N.P. edited and finalised the manuscript.

6. de Boer SA, Lefrandt JD, Petersen JF, Boersma $\mathrm{HH}$, Mulder DJ, Hoogenberg K. The effects of GLP-1 analogues in obese, insulin-using type 2 diabetes in relation to eating behaviour. Int $\mathrm{J}$ Clin Pharm. 2016; 38: 144-151.

7. Lee YS, Jun HS. Anti-Inflammatory Effects of GLP-1-based therapies beyond glucose control. Mediators Inflamm. 2016; 2016: 3094642.

8. Tran KL, Park YI, Pandya S, Muliyil NJ, Jensen BD, Huynh K, Nguyen QT. Overview of glucagon-like peptide-1 receptor agonists for the treatment of patients with type 2 diabetes. Am Health Drug Benefits. 2017; 10: 178-188.

9. Nadkarni P, Chepurny OG, Holz GG. Regulation of glucose homeostasis by GLP-1. Prog Mol Biol TransI Sci. 2014; 121: 23-65.

10. Shah M, Vella A. Effects of GLP-1 on appetite and weight. Rev Endocr Metab Disord. 2014; 15: 181-187. 
11. Drab SR. Glucagon-Like Peptide-1 receptor agonists for type 2 diabetes: a clinical update of safety and efficacy. Curr Diabetes Rev. 2016; 12: 403-413.

12. Sun F, Chai S, Yu K, Quan X, Yang Z, Wu S, Zhang Y, Ji L, Wang J, Shi L. Gastrointestinal adverse events of glucagon-like peptide-1 receptor agonists in patients with type 2 diabetes: a systematic review and network meta-analysis. Diabetes Technol Ther. 2015; 17: 35-42.

13. Sfairopoulos D, Liatis S, Tigas S, Liberopoulos E. Clinical pharmacology of glucagon-like peptide-1 receptor agonists. Hormones (Athens). 2018; 17: 333-350.

14. Davies MJ, D'Alessio DA, Fradkin J, Kernan WN, Mathieu C, Mingrone G, Rossing P, Tsapas A, Wexler DJ, Buse JB. Management of Hyperglycemia in Type 2 Diabetes, 2018. A Consensus Report by the American Diabetes Association (ADA) and the European Association for the Study of Diabetes (EASD). Diabetes Care. 2018; 41(12): 2669-2701. Epub 2018 Oct 4.

15. Cuthbertson DJ, Irwin A, Gardner CJ, Daousi C, Purewal T, Furlong N, Goenka N, Thomas EL, Adams VL, Pushpakom SP, Pirmohamed M, Kemp GJ. Improved glycaemia correlates with liver fat reduction in obese, type 2 diabetes, patients given glucagon-like peptide-1 (GLP-1) receptor agonists. PLoS One. 2012; 7: e50117.

16. Ryan D, Acosta A. GLP-1 receptor agonists: Nonglycemic clinical effects in weight loss and beyond. Obesity (Silver Spring). 2015; 23: 1119-1129.

17. Carretero Gómez J, Arévalo Lorido JC, Gómez Huelgas R, García de Lucas D, Mateos Polo L, Varela Aguilar JM, Seguí Ripoll JM, Ena J; Diabetes; Obesity; Nutrition Spanish Working Group. Combination Therapy With GlucagonLike Peptide-1 Receptor Agonists and SodiumGlucose Cotransporter 2 Inhibitors in Older Patients With Type 2 Diabetes: A Real-World Evidence Study. Can J Diabetes. 2018; pii: S1499-2671(18)30342-3.

18. Ghosal S, Sinha B. Liraglutide and Dulaglutide therapy in addition to SGLT-2 inhibitor and metformin treatment in Indian type 2 diabetics: a real world retrospective observational study. Clin Diabetes Endocrinol. 2018; 4: 11.

19. Filippatos TD, Panagiotopoulou TV, Elisaf MS. Adverse effects of GLP-1 receptor agonists. Rev Diabet Stud. 2014; 11: 202-230.

20. Montvida O, Green JB, Atherton J, Paul SK. Treatment with incretins does not increase the risk of pancreatic diseases compared to older anti-hyperglycaemic drugs, when added to metformin: real world evidence in people with Type 2 diabetes. Diabet Med. 2018 Oct 10. DOI: 10.1111/dme.13835.

21. Saraiva FK, Sposito AC. Cardiovascular effects of glucagon-like peptide 1 (GLP-1) receptor agonists. Cardiovasc Diabetol. 2014; 13: 142.

22. Drucker DJ. The cardiovascular biology of Glucagonlike Peptide-1. Cell Metab. 2016; 24: 15-30.

23. Takahashi A, Ihara M, Yamazaki S, Asanuma H, Asakura M, Kitakaze M. Impact of either GLP-1 agonists or DPP-4 inhibitors on pathophysiology of heart failure. Int Heart J. 2015; 56: 372-376.

24. Del Olmo-Garcia MI, Merino-Torres JF. GLP-1 receptor agonists and cardiovascular disease in patients with type 2 diabetes. J Diabetes Res. 2018; 2018: 4020492.

25. Marso SP, Daniels GH, Brown-Frandsen K, Kristensen P. Liraglutide and cardiovascular outcomes in type 2 diabetes. N Engl J Med. 2016; 375: 311-322.

26. Marso SP, Bain SC, Consoli A, Eliaschewitz FG, Jódar E, Leiter LA, Lingvay I, Rosenstock J, Seufert J, Warren ML, Woo V, Hansen O, Holst AG, Pettersson J, Vilsbøll T; SUSTAIN-6 Investigators. Semaglutide and cardiovascular outcomes in patients with type 2 diabetes. $\mathrm{N}$ Engl J Med. 2016; 375: 1834-1844.

27. Holman RR, Bethel MA, Mentz RJ, Thompson VP, Lokhnygina Y, Buse JB, Chan JC, Choi J, Gustavson SM, Iqbal N, Maggioni AP, Marso SP, Öhman P, Pagidipati NJ, Poulter N, Ramachandran A, Zinman B, Hernandez AF; EXSCEL Study Group. Effects of once-weekly exenatide on cardiovascular outcomes in type 2 diabetes. N Engl J Med. 2017; 377: 1228-1239.

28. Muskiet MHA, Tonneijck L, Huang Y, Liu M, Saremi A, Heerspink HJL, van Raalte DH. Lixisenatide in patients with type 2 diabetes and acute coronary syndrome. N Engl J Med. 2015; 373: 2247-2257.

29. Jia X, Alam M, Ye Y, Bajaj M, Birnbaum Y. GLP-1 Receptor agonists and cardiovascular disease: a meta-analysis of recent cardiac outcome trials. Cardiovasc Drugs Ther. 2018; 32: 65-72.

30.Lim S, Kim KM, Nauck MA. Glucagon-like peptide-1 receptor agonists and cardiovascular events: class effects versus individual patterns. Trends Endocrinol Metab. 2018; 29: 238-248.

31. Hernandez AF, Green JB, Janmohamed S, D'Agostino RB Sr, Granger CB, Jones 
NP, Leiter LA, Rosenberg AE, Sigmon KN, Somerville MC, Thorpe KM, McMurray JJV, Del Prato S; Harmony Outcomes committees and investigators. Albiglutide and cardiovascular outcomes in patients with type 2 diabetes and cardiovascular disease (Harmony Outcomes): a double-blind, randomised placebo-controlled trial. Lancet. 2018 Oct 1. [Epub ahead of print].

32. Nuffer W, Guesnier A, Trujillo JM. A review of the new GLP-1 receptor agonist/basal insulin fixedratio combination products. Ther Adv Endocrinol Metab. 2018; 9: 69-79.

33. Fadini GP, Sarangdhar M, Avogaro A. Glucagonlike peptide-1 receptor agonists are not associated with retinal adverse events in the FDA Adverse Event Reporting System. BMJ Open Diabetes Res Care. 2018; 6: e000475.

34. Boye KS, Botros FT, Haupt A, Woodward B, Lage MJ. Glucagon-Like Peptide-1 Receptor Agonist use and renal impairment: a retrospective analysis of an electronic health records database in the U.S. population. Diabetes Ther. 2018; 9: 637-650.

35. Andrikou E, Tsioufis C, Andrikou I, Leotsinis I, Tousoulis D, Papanas N. GLP-1 Receptor Agonists and cardiovascular outcome trials: an update. Hellenic J Cardiol. 2018; pii: S11099666(18)30408-1. [Epub ahead of print]. 